\title{
Chlorpropamide-Alcohol Flushing and Plasma Chlorpropamide Concentrations in Diabetic Patients on Maintenance Chlorpropamide Therapy
}

\author{
R.M.Hillson ${ }^{1}$, R. F.Smith ${ }^{2}$, H. Dhar ${ }^{1}$, R. A. Moore ${ }^{2}$ and T.D. R. Hockaday ${ }^{1}$ \\ ${ }^{1}$ Department of Diabetes and ${ }^{2}$ Nuffield Department of Clinical Biochemistry, Radcliffe Infirmary, Oxford, UK
}

\begin{abstract}
Summary. Forty-three diabetic patients on maintenance chlorpropamide (100-750 $\mathrm{mg}$ daily) drank $0.2 \mathrm{ml} / \mathrm{kg} 90 \%$ ethanol after equilibration in a room controlled at $20^{\circ} \mathrm{C}$. Twenty-five patients had already noted marked alcohol flushing since starting chlopropamide therapy (group A), while 13 had not observed this (group B). The remainder were teetotal or unsure of their reaction. Cheek temperature rise correlated with plasma chlorpropamide concentration $(r=0.6, p<0.001)$ in all patients and was inversely related to basal cheek temperature $(r=-0.35, p<0.02)$. Plasma chlorpropamide correlat-
\end{abstract}

ed with daily chlorpropamide dose $(r=0.8, p<0.001)$ but not with basal cheek temperature. The correlation between chlorpropamide level and cheek temperature rise was strengthened on analysis of group A alone $(r=0.7, p<0.001)$ and absent in group B $(r=0.2, p>0.3)$ who tended to have lower chlorpropamide levels and cheek temperature rise than group A.

Key words: Chlorpropamide-alcohol flushing, chlorpropamide, alcohol, flushing, body temperature, diabetes.
Among the early studies of chlorpropamide, Cardonnet et al. [1] stated that "... reactions of the vasomotor type accompanied by feverishness and facial flushing frequently broke out after ingestion of an alcoholic beverage, spontaneously receding within 30 minutes and failing to occur when the dose of the drug was reduced or the ingestion of alcohol was suspended". Recent interest in chlororopamide-alcohol flushing (CPAF) was stimulated by the observations of Leslie et al. [2] and Barnett and Pyke [3], who suggested that it was potentially important as a marker, or possibly a predictor of some of the complications of diabetes.

This study investigates factors associated with CPAF (measured by cheek temperature change), in particular the importance of plasma chlorpropamide concentration.

\section{Patients and Methods}

Diabetic patients from the Radcliffe Diabetic Clinic, who had received chlorpropamide for at least 6 months, were studied with informed written consent and Ethics Committee approval. The 43 patients $(31 \mathrm{men})$ took $100-750 \mathrm{mg}$ chlorpropamide daily. Twenty-five had noted marked flushing with alcohol at home only after starting chlorpropamide therapy (group A), while 13 had not noted this effect (group B). The remainder were teetotal or uncertain of the effect of alcohol but had not flushed before chlorpropamide therapy. Patients were studied the morning after an overnight fast, $<5 \mathrm{~h}$ after the last chlorpropamide dose, in a room with ambient temperature controlled at $20 \pm 0.3^{\circ} \mathrm{C}$ (mean $\pm \mathrm{SD}$ ). Cheek temperature was recorded continuously for at least $35 \mathrm{~min}$ before and $30 \mathrm{~min}$ after alcohol using surface thermocouples and a temperature recorder from Ellab, Copenhagen, Denmark. When their temperatures were steady, the subjects drank $0.2 \mathrm{ml} / \mathrm{kg}$ of $90 \%(\mathrm{v} / \mathrm{v})$ ethanol in two volumes of water. A venous blood sample was taken before ethanol ingestion, for the estimation of plasma glucose concentration by a standard glucose oxidase technique, and for plasma chlorpropamide concentration using gasliquid chromatography [4].

Non-parametric statistical analysis was used [5]. Variables are expressed as median (and range), and the significance of two-tailed tests as $p$.

\section{Results}

There was no significant difference in age, fasting plasma glucose or body mass index between groups A (previous flushing) and B (previous flushing not reported), but the former had a longer duration of diabetes (8.4 versus 6.0 years, $p<0.05$ ). After the test alcohol, significantly more patients were aware of facial warmth in group A (23) than in group B (5). All but three subjects had a visible facial flush, extending to the feet in two, and one man became breathless and wheezed.

Neither initial cheek temperature (group A: median: $31.2^{\circ} \mathrm{C}$, range: $28.5-33.3^{\circ} \mathrm{C}$; group $\mathrm{B}$ : median: $31.2^{\circ} \mathrm{C}$, range: $28.9-34.3^{\circ} \mathrm{C}$ ) nor cheek temperature 


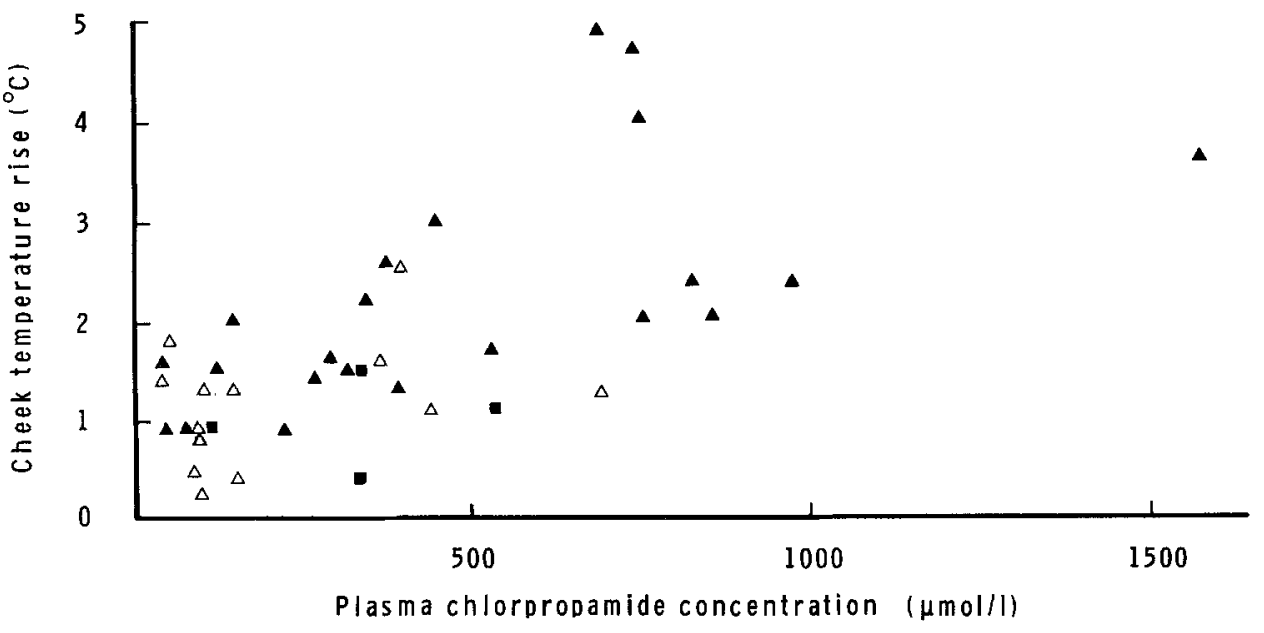

Fig. 1. Cheek temperature rise above baseline within $30 \mathrm{~min}$ after alcohol plotted against plasma chlorpropamide concentration in diabetic patients aware (group A $\mathbf{A}$ ) and unaware (group B $\triangle$ ) of chlorpropamidealcohol flushing at home; (teetotal or unsure $\mathbf{\square}$ rise differed significantly between the two groups, although the latter tended to be greater in known flushers (group A: median: $2.0^{\circ} \mathrm{C}$, range: $0.9-4.9^{\circ} \mathrm{C}$; group $\mathrm{B}$ : median: $1.2^{\circ} \mathrm{C}$, range: $0.3-2.5^{\circ} \mathrm{C}$ ). This cheek temperature rise above baseline within $30 \mathrm{~min}$ after alcohol correlated inversely with initial cheek temperature $\left(r_{\mathrm{s}}=-0.35, p<0.02\right)$.

Plasma chlorpropamide concentrations ranged from 39 to $1564 \mu \mathrm{mol} / 1$ (median: $325, n=39$ ) and tended to be higher in group A (range: $39-1564$; median: $368 \mu \mathrm{mol} / 1$ ) than group B (range: $50-1046$; median: $143 \mu \mathrm{mol} / \mathrm{l}$ ) but not significantly so. Plasma chlorpropamide correlated with cheek temperature rise in all 43 subjects $\left(r_{\mathrm{s}}=0.6, p<0.001 ;\right.$ Fig. 1$)$. When the two groups were analysed separately, this correlation was strengthened in group A $\left(r_{\mathrm{s}}=0.7, p<0.001\right)$ and absent in group $\mathrm{B}\left(r_{\mathrm{s}}=0.2, p>0.3\right)$.

Plasma chlorpropamide level correlated with daily chlorpropamide dose $\left(r_{\mathrm{s}}=0.8, p<0.001\right)$. Eight of the 13 group $B$ subjects were taking $100 \mathrm{mg}$ chlorpropamide only. When the 12 patients on $100 \mathrm{mg}$ chlorpropamide from both groups were analysed separately, there was no correlation between plasma chlorpropamide and cheek temperature rise.

The daily dose was correlated with cheek temperature rise in group A $\left(r_{\mathrm{s}}=0.5, p<0.004\right)$ but not group $\mathrm{B}\left(r_{\mathrm{s}}=0.4, p>0.1\right)$ although $r$ values are similar, significance level being determined by the numbers in each group. There was no correlation between basal cheek temperature or fasting plasma glucose and plasma chlorpropamide concentration. Fasting glucose was $>8 \mathrm{mmol} / \mathrm{l}$ in 14 patients.

\section{Discussion}

In 43 diabetic patients on long-term chlorpropamide therapy, cheek temperature rise on alcohol testing correlated with plasma chlorpropamide concentration, which in turn correlated with daily chlorpropamide dose, contrasting with the observations of Barnett et al. [6]. Cheek temperature rise was inversely correlated to basal cheek temperature, as in glucose flushing [7]. Group A patients had been diabetic for longer and tended to have greater plasma chlorpropamide concentration [8] and cheek temperature rise than group B.

When these two groups were analysed separately the relationship between cheek temperature rise and plasma chlorpropamide concentration was apparent only in group A and was not seen in the smaller asymptomatic group of whom $62 \%$ were on $100 \mathrm{mg}$ chlorpropamide only. However, this correlation did not occur in the patients on $100 \mathrm{mg}$ chlorpropamide from both groups.

Cheek temperature rise was a continuously distributed variable and although it tended to be greater in group A there was considerable overlap between the two groups as there was with plasma chlorpropamide concentration. The degree of cheek temperature rise was inversely related to initial cheek temperature and correlated with plasma chlorpropamide level. Both basal facial temperature and plasma chlorpropamide concentration merit further consideration in studies of chlorpropamide-alcohol flushing.

Acknowledgements. We thank the patients who took part in this study, Sister B.Pim, Mrs D. Renton, and the staff of the Nuffield Department of Clinical Biochemistry. The University of Oxford Medical Research Fund, the Oxford Diabetes Trust and the British Diabetic Association provided financial assistance.

\section{References}

1. Cardonnet LJ, Staffieri JJ, Eberhardt D, Tomasino PO, Berli RR, Muratorio J (1959) Clinical study of the effects of chlorpropamide on normal subjects and diabetics. Ann New York Acad Sci 74: 771-787

2. Leslie RDG, Barnett AH, Pyke DA (1979) Chlorpropamide-alcohol flushing and diabetic retinopathy. Lancet i: 997-999

3. Barnett AH, Pyke DA (1980) Chlorpropamide-alcohol flushing and large vessel disease in non-insulin dependent diabetes. Br Med J 2: $261-262$ 
4. Prescott LF, Redman DR (1972) Gas-liquid chromatographic estimation of tolbutamide and chlorpropamide in plasma. J Pharm Pharmac 24: 713-716

5. Siegel S (1956) Non-parametric statistics for the behavioural sciences. McGraw-Hill Kogakusha, Tokyo

6. Barnett AH, Gonzalez-Auvert C, Pyke DA, Saunders JB, Williams R, Dickenson CJ, Rawlins MD (1981) Blood concentrations of acetaldehyde during chlorpropamide-alcohol flush. Br Med J2: 939-941

7. Hillson RM, Hockaday TDR (1982) Facial and sublingual temperature changes following intravenous glucose injection in diabetics. Diabète et Métabolisme (Paris) 8: 15-19
8. Jerntorp P, Almèr L-O, Melander A (1981) Is the blood chlorpropamide concentration critical in the chlorpropamide alcohol flush? $\mathrm{Br}$ Med J 1: 165-166

Received: 29 January 1982

and in revised form: 9 September 1982

Dr. R. M. Hillson

Diabetic Office

Radcliffe Infirmary

Oxford OX2 6HE, UK 